\title{
As construções resultativas nas línguas românicas: um estudo com base na Gramática Cognitiva das Construções
}

\author{
Resultative Constructions in romance languages: \\ a study based on Cognitive Construction Grammar
}

Roza Maria Palomanes Ribeiro

Universidade Federal Rural do Rio de Janeiro (UFRRJ)

Seropédica, Rio de Janeiro, Brasil

rozapalomanes@terra.com.br

Resumo: Com base na Gramática Cognitiva das Construções, tal como vem sendo desenvolvida por Adele Goldberg $(1995,2006)$, esta pesquisa objetiva descrever construções que sinalizam resultatividade do português, uma vez que, através de estudos translinguísticos, tem-se defendido que as línguas românicas não apresentam tal construção, não havendo estudo significativo em língua portuguesa, por conseguinte. Para tanto, utilizaram-se as entrevistas do corpus Discurso \& Gramática (1995) para seleção de dados com o padrão construcional SN ficar SADJ. Promoveu-se uma extensa revisão bibliográfica de autores que estudaram, ainda que seguindo outras linhas de análise, o fenômeno das construções resultativas. Após seleção e análise dos dados, constatouse que, corroborando a hipótese inicial, o português criou mecanismos para expressar a resultatividade - não pode haver construção causativa, sem que haja uma resultativa que expresse o evento final - e que este mecanismo utiliza, preferencialmente, a forma sintática intransitiva [SN ficar SR], cuja semântica é [X torna-se Y].

Palavras-chave: construções resultativas; gramática cognitiva das construções. 
Abstract: Based on Cognitive Construction Grammar, such as it has been developed by Adele Goldberg $(1995,2006)$, this research aims to describe portuguese constructions that express resultativity, since throughout crosslinguistics studies, it has been defended that it is an impossible phenomenon in romance languages and there is not a significative study in Portuguese, thus. Therefore, we used interviews from Discurso \& Gramática corpus (1995) for selecting data with the constructional pattern NP ficar AP. It was made an extensive bibliographic revision of authors who study the resultative constructions phenomenon, even following other analytical lines. After data selection and analysis, it was noticed that Portuguese has created mechanisms to express resultativity - It cannot have a causative construction without a resultative to express the final event - and that this mechanism preferably uses the intransitive syntactic form [SN ficar SR], which semantics is [X torna-se Y].

Keywords: resultative construction; cognitive construction grammar.

Recebido em 14 de julho de 2015. Aprovado em 12 de outubro de 2015.

\section{Introdução}

Estudos recentes dentro do modelo teórico da Gramática das Construções (GC) têm apresentado reflexões acerca das idiossincrasias envolvendo as construções resultativas. Foi escolhida essa construção como objeto de estudo dessa pesquisa com o objetivo principal de comprovar que as línguas românicas apresentam construções do tipo resultativo, ao contrário do que apontam estudos translinguísticos anteriores.

$\mathrm{Na}$ literatura científica, estudos translinguísticos apontam que algumas línguas permitem a seus falantes colocarem verbo e adjetivo juntos, criando um predicado complexo comumente chamado de construção resultativa (CR). $\mathrm{O}$ alemão e o inglês ${ }^{1}$, por exemplo, são considerados línguas em que podem ocorrer as construções resultativas. Seguem alguns exemplos:

\footnotetext{
${ }^{1}$ Exemplos retirados do texto Building Resultatives de Angelika Kratzer (2004)
} 


\section{(1) Die Teekanne leer trinken \\ The teapot empty drink \\ * Beber a chaleira vazia.}

ACR tem sido central em muitos trabalhos recentes sobre estrutura argumental e interface semantico-sintática, em trabalhos com abordagens minimalistas da gramática (LEVIN; RAPPAPORT HOVAV, 1995) e construcionais (GOLDBERG, 1995; GOLDBERG; JACKENDOFF, 2004; BOAS, 2003). É caracterizada por um argumento semântico extra, o sintagma resultativo (SR), que indica o estado resultante de uma ação denotada pelo verbo. Observemos alguns exemplos em inglês:

(2) Mary painted the house red.

('Mary pintou a casa de vermelho.')

(3) The pond froze solid.

('O lago congelou sólido.')

Segundo Boas (2003, p.586), a CR descreve o estado de um argumento que resulta de uma ação denotada pelo verbo. Em (6), o verbo deve ser entendido como tendo causado o estado resultante.

(4) I cooked the carrots soft.

('Entende-se que as cenouras ficaram macias ao serem cozidas.')

Boas (2000), Carrier e Randall (1992), Goldberg (1995), Hoekstra (1984, 1992), Levin e Rappaport Hovav (1995,1999, 2001), Fontanals (2001), Wechsler (1997, 2001) e Goldberg e Jackendoff (2004) são exemplos de trabalhos significativos sobre resultativas na literatura científica mundial.

É importante citar que Pustejovsky (1991) e Rappaport Hovav e Levin (1998) vêm estudando as resultativas verdadeiras (RV) e as resultativas falsas (RF) encontradas no inglês. Segundo eles, nas RVs, o sintagma resultativo descreve um evento independente, não lexicalmente especificado pelo verbo, enquanto que nas RFs, o sintagma final não o descreve, mas modifica o estado final especificado lexicalmente pelo verbo. A seguir, há alguns exemplos retirados de Carrier e Randall (1992):

(5) Carol watered the roses flat. (*Terry aguou os narcisos achatados.) - RESULTATIVAS VERDADEIRAS. 
(6) John cut the bread into thick slices. (John cortou o pão em fatias finas.) - RESULTATIVAS FALSAS.

Para autores como Fontanals (2001, p. 83), nem todas as línguas (as Românicas, por exemplo) possuem esse tipo de construção resultativa do inglês, considerada "RV". No quadro 1, sintetiza-se a pesquisa desenvolvida por Fontanals (op. cit), como pode ser visto a seguir:

\section{QUADRO 1}

Síntese da pesquisa desenvolvida por Fontanals (2001)

\begin{tabular}{|l|l|}
\hline \multicolumn{1}{|c|}{$\begin{array}{c}\text { Línguas que permitem construções } \\
\text { resultativas verdadeiras }\end{array}$} & \multicolumn{1}{c|}{$\begin{array}{c}\text { Línguas que não permitem construções } \\
\text { resultativas verdadeiras }\end{array}$} \\
\hline Austroasiático (khmer) & Basco \\
Língua Americana de Sinais (ASL) & Afroasiático (egípcio, hebreu) \\
Finno-Ugric (húngaro) & Austronesiano (javanês) \\
Germânica (inglês, alemão) & Eskimo-Aleut (inuttu) \\
Japonês-Coreano (jpn., kor.) & Bantu (lingala) \\
Sino-tibetan (mandarim) & Românicas (francês, espanhol, português, italiano) \\
Tai & Eslavo (russo, servo-croata) \\
\hline
\end{tabular}

Fontanals (op.cit) provê uma explicação léxico-sintática para o porquê de sentenças resultativas como John hammered the metal flat (*João martelou o metal achatado) não existirem em línguas românicas. Para ele, em línguas como o inglês e o alemão, esta operação parece ser possível por serem línguas de natureza satellite-frame (c.f. TALMY, 1991, p.222). Em contraste, as línguas românicas de natureza verb-frame ${ }^{2}$ não permitem tal operação.

2 "Satélite" é o termo usado por Talmy (2000, p.102) para "certain immediate constituents of a verb root other than inflections, auxiliaries, or nominal arguments" Assim, verb framing se refere a como os sintagmas verbais em diferentes línguas variam de acordo como o verbo codifica o modo de movimento (manner of motion), como, por exemplo, correndo, andando, arrastando, ou a direção do movimento (direction of motion), como para dentro, através de, para fora. Esses dois conceitos podem ser codificados no verbo (como parte de sua raiz) ou em uma partícula separada associada ao verbo, chamada de satellite. Portanto, as línguas são dividas em satellite-framed languages ou verbframed languages. Os verbos em inglês utilizam partículas para expressar a direção do movimento ('run into', 'go out', 'fall down'), e seus verbos, em geral, expressam o modo de movimento. Portanto, o inglês é uma satellite-framed language. As línguas românicas como o português, por outro lado, apresentam muitos verbos de movimento 
Uma distinção crucial entre a RV, como em John hammered the metal flat, e a RF, como John cut the meat thin (João cortou a carne fina), deve ser feita. Segundo Talmy (2000, p.102), tanto em inglês como nas línguas românicas há RFs, mas somente línguas como o inglês possuem RVs.

Construções do português consideradas resultativas dada a similaridade sintática com as resultativas prototípicas do inglês, como João cortou a carne fina (John cut the meat thin), pertenceriam, segundo Fontanals (2001), ao grupo das RFs: thin (fina) pertence â classe dos adjetivos e, na construção dada como exemplo, ocupa a posição em que deveria figurar um advérbio.

Os estudos citados questionam a possibilidade de haver, nas línguas românicas, as RVs. Uma análise léxico-sintática, puramente, não consegue dar conta das CRs, uma vez que, como Goldberg e Jackendoff (2004, p.536) afirmam, as CRs apresentam uma variedade de sintaxe atrelada a um significado especial. Abordagens meramente formais não darão conta das possibilidades de se expressar resultatividade em uma língua.

Partindo das ideias exploradas pela Gramática das Construções (GOLDBERG, 1995, 2006), procuramos analisar especificamente a construção [SN ficar SADJ] (João ficou triste), observando a relação de reciprocidade existente entre a semântica da construção e a semântica do verbo. Assim, a estrutura sintática se liga ao significado da construção, e questões semânticas e pragmáticas influenciam no julgamento de gramaticalidade da construção.

Como objetivo específico desta pesquisa, pretendemos propor uma análise diferenciada desse tipo de construção de que o verbo ficar participa. Tradicionalmente, o verbo ficar em construções [Suj. FICAR pred.suj.] é apresentado sob o rótulo de verbo de ligação. Diferentemente dessa classificação que não leva em conta as diversas nuances de sentido que pode adquirir um verbo dependendo das relações que se estabelecem no interior das construções, propomos uma análise que leve em conta

como entrar, sair, subir, descer, que codificam a direção do movimento (para fora, para dentro, para cima e para baixo), expressando o modo de movimento através de um complemento no gerúndio, por exemplo, entrar correndo. Portanto, o português, assim como as demais línguas românicas, são verb-framed languages. 
a semântica da construção e a semântica do verbo, não deixando de se considerar, principalmente, o contexto discursivo.

As hipóteses levantadas são as seguintes:

- Hipótese principal: Em português, há construções que podem ser consideradas resultativas, ainda que não haja exemplos das resultativas consideradas prototípicas, com forma sintática [SN V SN SR].

- Hipóteses secundárias:

a) As construções mais produtivas, quando se trata de expressar resultatividade em português, são as que apresentam a forma sintática [SN V SR], tendo como verbo relacionado o ficar.

b) Num contexto mais amplo do discurso, deve haver uma construção a servir de CAUSA ao RESULTADO expresso em construções resultativas do tipo intransitivas.

Com esse aporte teórico-metodológico, empreende-se, então, a apresentação de uma proposta de ir além da tipologia descritiva até então feita nos estudos sobre variação translinguística entre as resultativas, classificar as construções em estudo com base na semelhança familiar na sintaxe e semântica com a resultativa de propriedade não causativa (GOLDBERG; JACKENDOFF, 2004) e utilizar dados contextualizados, retirados de entrevistas do corpus Discurso \& Gramática - Rio de Janeiro (VOTRE; OLIVEIRA, 1995).

\section{Fundamentação teórica}

A Gramática das Construções (GC) é uma das teorias que compõe o grupo de teorias relacionadas sob o rótulo de Linguística Cognitiva.

A Linguística Cognitiva (doravante LC) é uma abordagem da linguagem que surgiu a partir da década de 1970 e vê o conhecimento em conexão com as experiências de mundo do ser. São estudadas as unidades e as estruturas da linguagem como manifestações de capacidades cognitivas gerais, da organização conceptual, de princípios de categorização, de mecanismos de processamento e da experiência cultural, social e individual. São temas de especial interesse da LC, dentre outros, a interface conceptual entre sintaxe e semântica e a base pragmática ligada à experiência da linguagem no uso. 
Pela importância que atribui aos aspectos funcionais dos fenômenos linguísticos, e por desenvolver uma análise linguística com base na observação do uso linguístico (cf. LANGACKER, 1987), a LC é um tipo de linguística pragmaticamente orientada, tanto teórica como metodologicamente.

Para a LC, as categorias gramaticais são também, tal como as lexicais, entidades simbólicas, isto é, significativas. Elas devem, portanto ser consideradas não somente em termos das suas propriedades sintáticas, mas tendo em conta a sua base semântica.

Esta perspectiva simbólica da gramática encontra-se na Gramática das Construções, desenvolvida por Fillmore, Kay e O’Connor (1988), Goldberg $(1995,2006)$ e outros.

\subsection{Gramática das Construções: noções principais}

A GC foi desenvolvida nos anos 80 por Fillmore, Kay, Lakoff e outros. Trata-se de uma família de teorias sintáticas, mais que uma teoria unificada, cognitivamente baseadas, que compartilham princípios fundamentais.

A abordagem proposta por Goldberg $(1995,2006)$ é chamada de Gramática Cognitiva das Construções (GCC). Esta nos interessa em particular por fundamentar, teoricamente, este trabalho. A diferença entre a GCC e os demais modelos construcionistas como os que vêm sendo desenvolvidos por Paul Kay, Charles Fillmore, Langacker e outros, está, basicamente, no fato de ser um modelo baseado no uso.

A unidade preliminar da gramática, para a GCC, é a construção gramatical: a construção é vista como o princípio fundamental da organização gramatical, podendo ser qualquer elemento formal diretamente associado a algum sentido, a uma função pragmática ou contendo uma estrutura informacional. Essa definição de construção cobre uma variedade de unidades linguísticas que vai de morfemas simples a padrões sintáticos abstratos.

As estruturas sintáticas de uma língua não podem ser descritas somente segundo critérios sintáticos ou morfossintáticos, nem se levando em conta as propriedades sintáticas e semânticas dos verbos que as integram. Na verdade, as construções sintáticas possuem estruturas semânticas próprias. Assim, o significado da construção não corresponde à soma dos significados das unidades lexicais que a construção possui. 
Tanto as construções gramaticais quanto as unidades lexicais (assim como os morfemas em algumas construções gramaticais) são combinações de forma e significado, um continuum léxico-sintático. Esta é a principal hipótese da GCC: as gramáticas das línguas são compostas por pares de esquema conceptuais e padrões gramaticais que se inter-relacionam. Os esquemas associados às formas sintáticas representam a experiência humana mais básica (como movimento do corpo no espaço, por exemplo) e são como ferramentas com as quais organizamos nossa compreensão, estruturando percepções, imagens e eventos.

Sendo a unidade preliminar da gramática a construção, a GCC não subdivide a gramática de uma língua em componentes autônomos - os componentes fonológico, sintático e semântico - que possuem suas próprias regras combinatórias. A fonologia, a sintaxe e a semântica são partes integradas da construção individual.

Goldberg $(1995,2006)$ apresenta alguns argumentos a favor da existência de um significado próprio para as construções sintáticas:

(a) a inaceitabilidade de significados e usos especiais de certos verbos, uma vez que o mesmo verbo pode estar empregado ora intransitivamente, ora transitivamente, por exemplo.

(b) O significado da construção não é previsível por suas partes constituintes, i.e., seu significado independe do verbo com o qual se combina.

(c) A criança adquire o significado de um novo verbo colocado numa construção que ela já conhece, com facilidade.

Em outras palavras, o uso de um verbo numa construção sintática diferente não implica um significado diferente para esse verbo; o uso pode ser simplesmente determinado pelo significado da construção de que o verbo participa. Observe os seguintes exemplos:

(7) Ele passou a presidente.

(8) O caçula passou o mais velho.

(9) A chuva passou.

(10) Maria passou as novidades às colegas. 
Trata-se, portanto, de uma importante inovação trazida pela GCC: a estrutura argumental é determinada pelo verbo e pela construção. $\mathrm{O}$ verbo não muda seu sentido para licenciar argumentos extras. $\mathrm{O}$ sentido vem da construção em que é empregado e da forma como a construção combina semanticamente com o verbo para expressar o evento complexo.

Como já foi dito, a GCC não faz uma distinção rígida entre a semântica e a pragmática; ambas são vistas como partes integradas de uma construção. Algumas construções só fazem sentido em um contexto específico.

\section{Metodologia da pesquisa}

Antes de passar à explanação do corpus da pesquisa, ao tratamento dispensado aos dados e às hipóteses de trabalho, expõem-se, resumidamente, alguns fundamentos teóricos decorrentes da perspectiva adotada tomados como base para a presente pesquisa:

a) A GCC vê as construções como unidades básicas da língua e não como resultado da interação entre itens lexicais e regras sintáticas. As gramáticas das línguas são compostas por pares de esquemas conceptuais e padrões gramaticais que se inter-relacionam.

b) A estrutura argumental é determinada pelo verbo e pela construção, e o sentido vem da construção em que o verbo é empregado e da forma como a construção combina semanticamente com o verbo para expressar o evento complexo.

c) Para a GCC, as construções só fazem sentido em um contexto específico.

Interessa, portanto, a análise da construção [SN ficar SR] (a) identificar construções com determinado padrão gramatical e esquema conceptual que permita caracterizá-las como uma construção resultativa, (b) sinalizar que verbo(s) é (são) empregado(s) em tal construção de forma a combinar semanticamente com ela e (c) descrever, ampliando o foco para o contexto discursivo, a relação causa/efeito que se estabelece, em português brasileiro, não no âmbito da oração, mas, sim, no do discurso.

Esta pesquisa baseia-se em dados que apresentem "um ser sofrendo uma mudança de estado como resultado de uma ação expressa anteriormente no fluxo do discurso". Estes dados foram coletados 
do corpus Discurso \& Gramática - seção Rio de Janeiro (VOTRE; OLIVEIRA, 1995).

A coleta de dados pode ser resumida no quadro que se segue:

QUADRO 2

Especificação da coleta de dados

\begin{tabular}{|c|c|}
\hline $\begin{array}{c}\text { Fonte da coleta de dados: } \\
\text { Discurso \& Gramática - } \\
\text { seção Rio de Janeiro - } 1995\end{array}$ & Número de entrevistas pesquisadas \\
\hline $\begin{array}{l}\text { Total de informantes por ano } \\
\text { escolar }\end{array}$ & $\begin{array}{l}\text { CA (atual } 1^{\circ} \text { ano): } 15 \text { informantes } \\
\text { alfabetização de adultos (atual EJA) - } 8 \text { informantes } \\
4 \text { a série (atual } 5^{\circ} \text { ano) do ensino fundamental (EF) - } \\
34 \text { informantes } \\
8 \text { a série (atual } 9^{\circ} \text { ano) do EF- } 12 \text { informantes } \\
\text { 3a série do ensino médio - } 16 \text { informantes } \\
\text { último ano do curso superior - } 8 \text { informantes }\end{array}$ \\
\hline Amostra & Total de entrevistas: 93 Total de dados coletados: 44 \\
\hline
\end{tabular}

Optou-se por um tratamento qualitativo e quantitativo dos dados. Acreditamos que a opção atende ao principal objetivo da pesquisa que é descrever construções que sinalizam resultatividade do português. No entanto, para corroborar a hipótese de que a construção [SN ficar SR] é produtiva no português brasileiro quando se trata de expressar resultatividade, será preciso apresentar quantificar.

Analisaram-se os dados em função do que é postulado pela GCC, de que a unidade preliminar é a construção gramatical. Partiuse da hipótese de que, em português, há construções que podem ser consideradas resultativas, ainda que não haja exemplos das resultativas consideradas prototípicas, apresentados na próxima seção, e que das construções encontradas, as mais produtivas, quando se trata de expressar resultatividade, são as que apresentam o verbo ficar.

Contrariamente a todos os estudos translinguísticos sobre resultativas em língua românicas, postulamos que tais construções apresentam semelhança familiar com as resultativas de propriedade não causativa, estudadas por Goldberg e Jackendoff (2004). 


\section{SN ficar SADJ: a construção resultativa do português}

As construções do tipo [SN FICAR SADJ] são analisadas ora isoladamente, sob o rótulo de verbo de ligação (a), i.e., como aquele esvaziado de sentido e, por isso, sem conteúdo ideativo, ora como parte de uma construção causativa biclausal (b), ora como uma construção passiva analítica (c). Observe os exemplos:

(a) O menino ficou triste.

(b) Ela fez o menino ficar triste.

(c) $\mathrm{O}$ forte ficou cercado pelo inimigo.

Em outra direção, esta pesquisa propõe que tal construção é a utilizada no português para indicar resultatividade, muito embora haja estudos translinguísticos que afirmem que nas línguas românicas não haja RVs.

Goldberg e Jackendoff (2004) desenvolveram um estudo que visava mostrar que as CRs apresentam uma variedade de sintaxe atrelada a um significado especial, impondo restrições especiais. Os autores apresentaram uma proposta de tratar as resultativas como um tipo de "família" construcional que partilham propriedades importantes, mas diferem em certas especificidades.

Uma característica identificadora de uma resultativa é um SAdj ou SPrep ocupando uma posição normal de um argumento verbal. Goldberg e Jackendoff (2004, p.536-538) nomeiam tal sintagma de sintagma resultativo (SR).

As resultativas foram subdividas pelos referidos autores em (a) transitivas e (b) intransitivas:

(a) John hammered the metal flat (*João martelou o metal achatado).

(b) The pond froze solid (O lago congelou sólido).

Os autores observam, ainda, outras dimensões de variação: resultativas de propriedade (property resultatives) vs. resultativas de percurso (path resultatives) e resultativas não causativas (noncausative resultatives) vs. resultativas causativas (causative resultatives). 
Para os autores, há um ponto crucial em que a CR começa a se fragmentar em um número de subconstruções distintas, com sintaxe similar, com estrutura argumental similar e subeventos construcionais similares, em que cada subconstrução apresenta suas próprias peculiaridades e restrições.

Defendemos que o português brasileiro apresenta uma construção sintática que expressa uma situação como resultado de outro evento, expresso em outra cláusula. E que esta construção seria a resultativa mais produtiva nessa língua Observe:

(9) O vidro da porta estorou e voou na cara dele (1), ele não se machucou seriamente mas a sua cara ficou cheia de sangue (2). (informante 1)

O evento causador ${ }^{3}$ e o evento resultativo são expressos cada um em sua cláusula, podendo-se observar que (1) sinaliza o elemento afetado que, no enunciado 2, passa a ser o sujeito.

Tal como apresentam Goldberg e Jackendoff (2004), as construções do tipo [SN ficar SR] apresentam o evento designado pelo verbo ficar associado ao argumento do sujeito afetado, expressando a permanência do sujeito em novo estado resultante e o evento causativo, que é expresso em outra cláusula, conferiria à construção com o ficar um caráter resultativo: subentende-se uma causatividade resultando em novo estado, pois está claro que o sujeito experimenta uma modificação, física ou psicológica, em que se pressupõe uma causa desencadeando o processo.

A causação é uma construção mental, de base experiencial, que compreende vários conceitos causais distintos, prototipicamente estruturados. Dois importantes modelos cognitivos de causação são o de "fazer" e o de "deixar". Analisando agora as construções [SN ficar $\mathrm{SR}$ ], percebe-se que os eventos verbais expressos em (10a) podem ser parafraseados como em (10b) de modo que a causação torna-se aparente:

\footnotetext{
${ }^{3}$ Identificamos nos dados que o evento causador pode ser agentivo ou instrumental, entendendo-se por caso instrumental força ou objeto inanimado, causalmente implicado na ação ou estado identificados pelo verbo.
} 
(10a) Depois de um mes de namoro ele terminou o namoro assim sem mais nem menos e a garota ficou super triste, ficou muito magoada. (informante 2)

(10b) O término do namoro deixou-a super triste, muito magoada. (X [agir] CAUSA Y TORNAR-SE Z)

Analisando [SN ficar SR], percebe-se que os eventos verbais expressos em (10a) e (11a) podem ser parafraseados como em (10b) e (11b), respectivamente, de modo que a causação torna-se aparente:

(11a) daí ele ficou louco porque tinham roubado/ o carro dele... o carro dele não era tão novo assim mas... pô... fazia a maior falta e tal...(informante 3 )

(11b) O roubo do carro deixou-o louco. (X [agir] CAUSA Y TORNAR-SE Z)

Ainda que sintaticamente o padrão seja diferente da resultativa apresentada como prototípica ou RV, tais construções apresentam propriedades típicas da CR: descrevem um resultado causado por uma atividade e apresentam um SR em posição argumental.

As CRs apresentam uma grande variação semântica e sintática, como afirmam Goldberg e Jackendoff (2004, p.532). Os referidos autores consideram um erro tratar a construção resultativa como um fenômeno único. As resultativas foram tratadas como formando uma "família" de construções, chamadas de subconstruções da Resultativa, partilhando importantes propriedades e diferindo em certas especificidades.

Uma característica que identifica uma construção resultativa é um SAdj ou SPrep que ocupa a posição de um argumento do verbo, chamado por Goldberg de sintagma resultativo (SR). Deve-se distinguir, numa análise classificatória, o que é adjunto do que são sintagmas argumentais; os adjuntos não designam estados resultativos contingentes das propriedades do verbo.

Semanticamente, o subevento construcional das resultativas apresenta variação quanto à causatividade; há construções resultativas (a) não causativas como, por exemplo, The pond froze solid (*O lago congelou sólido) e (b) causativas, como Ela cortou a cebola em rodelas. 
Não encontramos construções do tipo apresentado em (a) no português (as línguas românicas não apresentam este tipo de construção); na verdade, só se expressa a mudança de estado com o verbo ficar e verbos que podem ser usados no mesmo contexto como tornar-se, acabar, virar, fazer-se, etc. (todos eles classificados tradicionalmente como verbos de ligação quando indicam mudança de estado), ou com construções do tipo exemplificado em (b), consideradas por alguns autores, como visto como "falsas resultativas".

Visto isto, defendemos que o português do Brasil apresenta duas únicas construções que podem ser tratadas como resultativas: as construções do tipo João cortou o queijo em fatias e as construções com o verbo ficar. Afirmamos, também, que as construções resultativas com o verbo ficar, em contextos reais, apresentam-se como as mais frequentes.

Sintaticamente, as construções resultativas com o verbo ficar se assemelham às construções resultativas de propriedade não causativa apresentadas por Goldberg e Jackendoff (2004). A diferença entre elas está, além do tipo de verbo utilizado, no fato de que as construções de mudança de estado apresentam um único evento que indica X TORNARSE Y. O outro evento, que é entendido como algo causando a mudança expressa pelo evento central da cláusula com ficar, vem, em geral, em cláusula anterior do mesmo discurso.

\section{Análise das construções resultativas com o verbo ficar: uma proposta de revisão nos conceitos de resultatividade expressos nas línguas românicas}

Esta seção inicia a análise dos dados recolhidos para estudo. Passa-se à análise das CRs do português de acordo com os princípios expostos na GCC.

Foram estabelecidos como dados relevantes para o estudo aqueles que apresentavam as construções resultativas com o verbo ficar já exemplificadas em anteriormente (doravante tipo I) e as construções do tipo João cortou a cebola em rodelas ${ }^{4}$ (doravante tipo II).

\footnotetext{
${ }^{4}$ A guisa de informação, consideramos como construções do tipo II as que apresentavam o seguinte formato, independentemente do verbo utilizado:
} 
A seleção de dados feita confirmou a hipótese secundária de que a construção resultativa com o verbo ficar é a mais produtiva em português: dos 44 dados que caracterizam construções do tipo resultativas, 38 são construções do tipo I e apenas 06 do tipo II, como pode ser visto na tabela 1:

\section{TABELA 1}

Construções resultativas retiradas do corpus $\mathrm{D} \& \mathrm{G}$

\begin{tabular}{|l|l|}
\hline Total de construções resultativas & $44(100 \%)$ \\
\hline Resultativas do tipo I & $38(87 \%)$ \\
\hline Resultativas do tipo II & $6(13 \%)$ \\
\hline
\end{tabular}

Fonte: VOTRE \& OLIVEIRA, 1995.

Verificou-se a necessidade de ampliar o contexto analítico, observando as relações de causa e efeito dentro do discurso: uma das hipóteses secundárias iniciais era a de haver, num contexto mais amplo do discurso, uma construção a servir de CAUSA ao RESULTADO expresso em construções resultativas do tipo I, pois nas do tipo II a causa e o resultado vêm expressos na mesma cláusula. Em todas as ocorrências encontradas, foram percebidas tais relações, o que confirma nossa ideia inicial: em 11 ocorrências (29\%), o evento causativo vem antes da resultativa, sendo que o objeto da construção que expressa o evento causador retomado como sujeito da resultativa. Observe-se o exemplo a seguir em que a frase em negrito sinaliza o resultado de uma brincadeira feita em um local de trabalho com um estagiário novo:

(13) ...entrou esse novo estagiário... eu falei "pô... qual o (nome)?" "ah:: o nome dele é Arruda... André..." eu falei "ih... arruda é pra tirar olho grande..." aí o cara... sério... "arruda nada... eu sou cristão... não acredito em nada disso..." não sei quê... aí o pessoal sacaneou... e tem uma Áurea... que é uma baixinha... gordinha... que também é:: designer ((riso)) ela é baixinha e ela é muito sacana... então (nessa) sacanagem dela... o cara/ começou a sacanear o cara... aí o cara foi ficando mais puto... quer dizer... de um fato engraçado começou um fato/ saiu pra um constrangedor... que ela foi ficando tão/ o cara ficou tão puto... que chegou uma certa hora que::... ela parou... aí o pessoal começou todo mundo a rir...(Informante 4) 
O enunciado começou a sacanear o cara é onde se inicia a ação causadora, o evento causador. O conteúdo semântico expresso estabelece a causatividade e a resultatividade entre os eventos começou a sacanear e ficou puto. O que ocorre, ampliando-se o contexto observado, é uma construção representando o evento causador e outra sinalizando o resultado da ação expressa na cláusula causativa.

Em 08 ocorrências (21\%), foi possível perceber que o evento causador não vem expresso, somente, antes da cláusula resultativa no discurso; ele pode vir após a resultativa, na forma de uma oração hipotática, que, nos casos estudados eram adverbiais causais ou temporais com leitura causal, em que se justifica ou se apresenta a causa para o efeito expresso. Observe, agora, o exemplo em que isto ocorre:

(14) Depois do bar, nós resolvemos ir para casa, no Grajaú. Eu peguei o carro e fui dirigindo alucinadamente até que no Rebouças, um Voyage surgiu na minha frente e eu não pude desviar. Depois da batida eu perdi a direção do carro e ele foi se arrastando uns cem metros pelo paredão do túnel. 1A Andréia que estava do meu lado e com o vidro aberto, ficou desesperada, 2 porque além do nervosismo da batida, a fuligem e a sujeira do paredão voou toda na cara dela e ela estava toda preta. Ela começou a gritar para eu tirar o carro dali e ir embora, só que o carro não andava de jeito nenhum. (informante 5)

É possível perceber no exemplo 14 a causalidade expressa pela oração 2, pois a fuligem e da sujeira terem "voado" na "cara" de Andréia é a causa de seu desespero, além do nervosismo da batida. E, ainda que não haja uma ação direta expressa nesta oração de um agente causador sobre Andréia, há uma causa primária, a batida, que fez o carro ser arrastado pelo túnel, desprendendo fuligem e sujeira sobre seu rosto.

Foram encontradas, ainda, 19 ocorrências (50\%) em que o objeto da causativa não foi recuperado como sujeito da resultativa. No entanto, foi possível perceber, nesses casos, relações metonímicas entre os mesmos, tais como instrumento/agente, propriedade/proprietário e parte/todo. Tal fato pode ser visto em: 
(15) oh... my ((riso)) uma história que tenham me contado? ai... dá pra desligar? ((o gravador)) meu irmão estava me contando outro dia que:.... ele conheceu um... um cara lá em Friburgo... que (C) roubaram o carro dele... há pouco tempo aqui em Fri/ aqui no Rio... na Glória... (R)daí ele ficou louco porque tinham roubado o carro dele... o carro dele não era tão novo assim mas... pô... fazia a maior falta (Informante 3 )

Neste trecho, o objeto da causativa (C) o carro dele e o sujeito da resultativa $(\mathrm{R})$ ele estão dentro de um mesmo domínio, havendo uma relação de contiguidade, designada por objeto/dono; há, portanto, um link metonímico entre o carro dele e ele.

Assim, confirmaram-se as hipóteses iniciais de que o português brasileiro há construções que podem ser consideradas resultativas, ainda que não haja exemplos das resultativas consideradas prototípicas, com forma sintática [SN V SN SR] e que as mais frequentes, quando se trata de expressar resultatividade em português, são as que apresentam a forma sintática [SN V SR], tendo como verbo relacionado o ficar.

\section{Considerações Finais}

Este artigo não pretende ser, e nem pode, a última palavra sobre resultatividade na língua portuguesa. Ela deve ser discutida como uma proposta, dentre outras.

Com relação aos resultados alcançados com a pesquisa, acreditamos ter atingido nossos objetivos, pois foi identificada uma construção em português brasileiro com um padrão gramatical e um esquema conceptual que a caracteriza como uma construção resultativa.

Como hipótese, aventamos que as construções mais frequentes quando se trata de expressar resultatividade em português brasileiro são as que apresentam a forma sintática [SN V SR], tendo como verbo relacionado o ficar. Tal hipótese foi corroborada quando identificamos, dentre as 44 resultativas encontradas no corpus, 38 que apresentavam esse padrão sintático, com semântica [X torna-se $\mathrm{Y}]$, tendo como verbo preferencial o ficar. Dessas 38 ocorrências encontradas, em 11 casos $(29 \%)$ a construção causativa vem antes da resultativa, tendo seu objeto retomado como sujeito da resultativa. Isto comprova ainda mais a relação de causa e efeito que se estabelece no discurso. 
Ainda que tenham sido encontradas 19 ocorrências $(50 \%)$ em que o objeto da causativa não foi recuperado como sujeito da resultativa, pode-se perceber, nesses casos, algumas relações metonímicas entre eles, tais como instrumento/agente, propriedade/proprietário e parte/todo.

No que concerne a estudos já existentes sobre o tema, esta pesquisa significa uma contribuição a mais. Pretende-se que, a partir deste ponto, novos interesses pelo assunto se apresentem. Assim, teremos certeza de ter contribuído, de alguma forma, para a investigação do fenômeno das resultativas do português brasileiro.

\section{Referências}

BOAS, H. C. Resultative constructions in English and German. $234 \mathrm{f}$. PhD (Dissertation) - University of North Carolina, 2000.

BOAS, H. C. A constructional approach to resultatives. Stanford: CSLI Publications, 2003.

BRESNAN, J. Control and complementation. Linguistic Inquiry, v. 13, n. 3, p. 343-434, 1997.

CARRIER, J.; RANDALL, J. H. The argument structure and syntactic structure of resultatives. Linguistic Inquiry, v. 23, n. 2, p. 173-234, 1992.

FILLMORE, C., J.; KAY, P.; O'CONNOR, M. C. Regularity and idiomaticity in grammatical constructions: the case of let alone. Language, v. 64, n. 3, p. 501-538, 1988.

FONTANALS J. M. Unselected objects. In: DEHE, Nicole; WANNER, Anja (Eds.). Structural aspects of semantically complex verbs. Frankfurt am Main: Peter Lang, 2001. p. 83-104.

GOLDBERG, A. E. Constructions: a construction grammar approach to argument structure. Chicago: Chicago University Press, 1995.

GOLDBERG, A. E. Constructions at work: the nature of generalization in language. Oxford: Oxford University Press, 2006.

GOLDBERG, A. E.; JACKENDOFF, R. The English resultative as a family of constructions. Language, v. 80, n. 3, p. 532-568, 2004.

HOEKSTRA, T. Transitivity: grammatical relations in government and binding theory. Dordrecht: Foris Publications, 1984. 
HOEKSTRA, T. Aspect and theta theory. In: ROCA, I. M. (Ed.). Thematic structure: its role in grammar. Dordrecht: Foris Publications, 1992. p. 145-174.

LANGACKER, R. Foundation of cognitive grammar: theoreticals prerequisites. Stanford, CA.: Stanford University Press, 1987. Vol. I.

LEVIN, B.; M. RAPPAPORT H. Unaccusativity: at the syntax-lexical semantics interface. Cambridge (Mass.): The MIT Press, 1995.

LEVIN, B.; M. RAPPAPORT H. Two structures for compositionally derived events. Proceedings of SALT 9, Cornell Linguistics Circle Publications, Cornell University, Ithaca, NY, 1999. p. 199-223.

LEVIN, B.; M. RAPPAPORT H. An event structure account of English resultatives. Language, v. 77, n. 4, p. 766-797, 2001.

PUSTEJOVSKY, J. The syntax of event structure. Cognition, v. 41, n. 1-3, p. 47-81, 1991.

RAPPAPORT H.; LEVIN, B. Building verb meanings. In: BUTT, M.; GEUDER, W. (Eds.). The projection of arguments: lexical and compositional factors. Stanford (CA): CSLI Publications, 1998. p. 97-134.

TALMY, L. Toward a cognitive semantics. Cambridge (Mass.): The MIT Press, 2000. 2 vols.

TALMY, L. Path to realization: a typology of event integration. Proceedings of the Seventeenth Annual Meeting of the Berkeley Linguistics Society: General Session and Parasession on The Grammar of Event Structure. Berkeley: Berkeley Linguistics Society, 1991. p. 480-519.

VOTRE, S.; OLIVEIRA, M. R. (Coord.). Discurso \& Gramática: a lingua falada e escrita da cidade do Rio de Janeiro. Rio de Janeiro: UFRJ, 1995.

WECHSLER, S. Resultative predicates and control. Texas Linguistic Forum, 38, 1997.

WECHSLER, S. An analysis of English resultatives under the eventargumenthomomorphism model of telicity. Proceedings of the $3 \mathrm{rd}$ Workshop on Text Structure. Austin: University of Texas, 2001. 